\title{
EFEITOS DA PRÁTICA DE EXERCícIO FíSICO EM PESSOAS COM LESÃO DA MEDULA ESPINHAL.
}

\author{
Kelly Arisa Nakamatsu*, Pâmella Kawane de Melo Pereira*, Vitória Alves da Silva*, Fernando Rosch de Faria, \\ Mariane Borges, José Irineu Gorla.
}

\section{Resumo}

O objetivo deste projeto foi identificar os efeitos do treinamento de handebol e rugby em cadeira de rodas desenvolvido de forma recreativa, na força muscular e capacidade aeróbia de indivíduos com lesão da medula espinhal (LME). Para atingir o objetivo traçado os participantes foram avaliados pré e pós aproximadamente cinco meses de prática esportiva e desta forma podemos identificar que não houveram melhoras significativas nas variáveis estudadas.

Palavras-chave: Lesão da medula espinhal, Exercício Físico, Avaliação.

\section{Introdução}

A prática esportiva de rendimento por pessoas com LME como o handebol (HCR) e o rugby em cadeira de rodas (RCR), promovem a redução do risco cardiovascular (MATOS-SOUZA et al., 2016), melhora da função diastólica (De ROSSI, et al., 2014) e melhora da composição corporal (GORLA et al., 2016). Todavia, até o presente momento não foi descrita pela comunidade científica possíveis melhoras na aptidão física através da prática destas modalidades esportivas de forma recreativa. Diante disto, este estudo teve por objetivo identificar os efeitos do treinamento de handebol e rugby em cadeira de rodas desenvolvido de forma recreativa, na força muscular e capacidade aeróbia de indivíduos com lesão da medula espinhal (LME).

\section{Resultados e Discussão}

Participaram deste estudo seis homens com LME sendo quatro paraplégicos praticantes de $\mathrm{HCR}$ e dois tetraplégicos praticantes de RCR a mais de três anos. A força muscular da articulação do cotovelo (flexão e extensão) foi avaliada através do teste concêntrico no dinamômetro isocinético. Para avaliação capacidade aeróbia foi utilizado teste de esforço cardiorrespiratório incremental máximo no ciclo ergômetro de braço e uma máscara facial de silicone conectada a um analisador de gases automatizado Oxycon. $\mathrm{O} \mathrm{VO}$ 2pico foi definido como valor médio dos últimos 30 segundos do teste.

Tabela 1. Pico de Torque.

\begin{tabular}{cccccccccc}
\hline & \multicolumn{4}{c}{ Direita } & \multicolumn{4}{c}{ Esquerda } \\
\hline & \multicolumn{3}{c}{ FLEX } & \multicolumn{2}{c}{ EXT } & \multicolumn{3}{c}{ FLEX } & \multicolumn{3}{c}{ EXT } \\
\hline Sujeito & Pré & Pós & Pré & Pós & Pré & Pós & Pré & Pós \\
\hline $\mathbf{1}$ & 80 & 57 & 78 & 71 & 71 & 51 & 97 & 59 \\
$\mathbf{2}$ & 73 & 86 & 100 & 84 & 76 & 81 & 101 & 66 \\
$\mathbf{3}$ & 70 & 72 & 65 & 61 & 64 & 64 & 54 & 50 \\
$\mathbf{4}$ & 57 & 70 & 50 & 51 & 54 & 63 & 31 & 42 \\
$\mathbf{5}$ & 57 & 71 & 80 & 54 & 59 & 71 & 69 & 67 \\
$\mathbf{6}$ & 79 & 77 & 67 & 34 & 71 & 52 & 68 & 43 \\
\hline
\end{tabular}

Tabela 2: Resultados capacidade aeróbia.

\begin{tabular}{ccccc}
\hline Sujeitos & \multicolumn{2}{c}{ VO $_{\text {2pico }}$} & \multicolumn{2}{c}{ RER } \\
\hline & Pré & Pós & Pré & Pós \\
\hline 1 & 14,68 & 10,9 & 1,18 & 1,69 \\
2 & 14,67 & 11,4 & 1,22 & 1,72 \\
3 & 20,05 & 17,84 & 1,17 & 1,68 \\
4 & 14,3 & 12,7 & 0,94 & 1,23 \\
5 & 13,06 & 12,18 & 1,16 & 1,52
\end{tabular}

Legenda: $\mathrm{VO}_{2 p i c o}=$ consumo de oxigênio pico; RERpico=taxa de troca respiratória.

Através dos resultados podemos observar que a maioria dos participantes tiveram redução da força muscular de extensão representada pelo Pico de Torque. Dentre os fatores que podem ter influenciado nesta redução da força muscular para extensão da articulação do cotovelo podemos citar a ausência de um "programa" de flexibilidade. Visto que a flexibilidade/amplitude de movimento tem relação com os níveis de força muscular, musculaturas contraídas, tensas e rígidas com volume excessivo de massa muscular limitam a amplitude do movimento (PLATONOV, 2008).

Quanto a redução da capacidade aeróbia, a mesma pode estar relacionada ao aumento da massa corporal e também a característica do treinamento, pois pode ser observado o aumento da taxa de troca respiratória que pode indicar que os treinamentos realizados utilizaram mais do metabolismo glicolítico (JACOBS et al., 2002), ou seja, que possuíram características anaeróbias.

\section{Conclusões}

Através desta pesquisa podemos observar que a prática do handebol e rugby em cadeira de rodas de forma recreativa não traz melhoras significativas na força muscular e capacidade aeróbia de indivíduos com LME.

MATOS-SOUZA, J. R.; et al. Impact of adapted sports activities on the progression of carotid atherosclerosis in spinal cord-injured subjects. Archives of physical medicine and rehabilitation, v. 97, n. 6, p. 1034-1037, 2016.

JACOBS, P. L.; et al. Circuit resistance training in persons with complete paraplegia. Journal of Rehabilitation Research and Development, v. 34, n.1 p. 21-28, 2002. 